\title{
Wpływ obróbki cieplnej po spawaniu na własności i strukturę złączy ze stali 4330V
}

\author{
Effect of heat treatment after welding \\ on the properties and structure of steel joints 4330V
}

\section{Streszczenie}

W artykule opisano wpływ obróbki cieplnej po spawaniu metodą MAG złączy wykonanych ze stali 4330V (CrNiMoV) na ich własności i strukturę. Złącza spawano w osłonie gazu M21, z użyciem materiału dodatkowego Böhler X 90-IG. Wybór drutu był uwarunkowany składem chemicznym oraz wysokimi własnościami wytrzymałościowymi stali. Blachy podgrzano wstępnie przed spawaniem do temperatury około $300{ }^{\circ} \mathrm{C}$. Po spawaniu przeprowadzono obróbkę cieplną, która polegała na wygrzaniu złączy w różnych temperaturach celem ich odpuszczenia. Następnie uzyskane połączenia zostały poddane badaniom wizualnym, badaniom makro i mikroskopowym, pomiarowi twardości, badaniom udarności, wytrzymałości na rozciąganie oraz próbie zginania. Przeprowadzone badania wykazały barak widocznych pęknięć w gotowych złączach. Stwierdzono zmiany strukturalne w obrębie SWC, co potwierdziły pomiary twardości w tych obszarach. Skutkowało to wystąpieniem pęknięć w złączach podczas prób zginania. Badania wytrzymałości na rozciąganie oraz udarności potwierdziły wysokie własności wytrzymałościowe gotowych złączy. Na podstawie przeprowadzonych badań ustalono optymalną obróbkę cieplną złączy spawanych ze stali $4330 \mathrm{~V}$ po spawaniu pod zapewniającą wysokie własności wytrzymałościowych i plastycznych.

Słowa kluczowe: stal 4330V; spawanie MAG; obróbka cieplna po spawaniu

\begin{abstract}
The article describes the effect of heat treatment after welding MAG joints made of steel $4330 \mathrm{~V}$ (CrNiMoV) on their properties and structure. Connectors welded gas shielded M21, with additional material Böhler X 90-IG. Selecting the wire was determined the chemical composition and properties of high strength steel. Sheets preheated before weIding to temperatures of about $300{ }^{\circ} \mathrm{C}$. After welding, heat treatment was carried out, which consisted of annealing joints at different temperatures purpose of their forgiveness. Then obtained connections were visually examined, tested macro and microscopic, measurement of hardness, impact testing, tensile and bending test. The study showed hut visible cracks in the finished joints. It was found structural changes within the SWC, which confirmed the hardness measurements in these areas. This resulted in the occurrence of cracks in the joints bend test. Studies tensile strength and impact strength showed the high strength properties of the finished connectors. Based on the study determined the optimal heat treatment of welded joints in steel $4330 \mathrm{~V}$ welding in providing high mechanical properties and plasticity.
\end{abstract}

Keywords: steel 4330V; welding MAG; post weld threatment

\section{Wstęp}

Stale drobnoziarniste to jedne z najbardziej rozwijanych gatunków stali w współczesnym świecie. Wraz z rozwojem technologii materiałowych możliwe jest uzyskanie coraz to nowych gatunków o bardzo wysokich własnościach wytrzymałościowych. Dobór poszczególnych pierwiastków stopowych i przeprowadzenie odpowiednich zabiegów cieplnych oraz mechanicznych nie daje pewności, że taki materiał będzie zachowywał swoje własności w wszystkich warunkach produkcyjnych czy też eksploatacyjnych $[1,2]$. W przypadku stali obrobionych cieplnie sprawy komplikują się dodatkowo, ponieważ materiał dostarczany jest w stanie gotowym. Wszystkie zabiegi technologiczne, które nagrzewają materiał, mogą doprowadzić do degradacji struktury wewnętrznej dzięki której uzyskuje się wysokie własności wytrzymałościowe $[1,2]$. Uzyskanie odpowiedniej struktury oraz własności wytrzymałościowych i plastycznych wymaga dobrania odpowiednich pierwiastków stopowych oraz mikrododatków takich jak wanad, tytan, niob. Dzięki precyzyjnemu doborowi dodatków stopowych można w pewnym za-

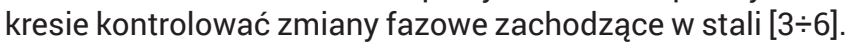
Pierwiastki stopowe a bardziej mikrododatki są dodawane, aby osiągnąć pewne pożądane efekty w stali. Dlatego też wanad dodaje się, aby uzyskać efekt utwardzenia wydzieleniowego stali, w przypadku tytanu, niobu uzyskuje się efekt rozdrobnienia ziarna, dzięki czemu stal wykazuje lepsze własności wytrzymałościowe. W stalach obrobionych cieplnie

Mgr inż. Marcin Żuk - Politechnika Śląska.

Autor korespondencyjny/Corresponding author. marcin.zuk@polsl.pl 
dodatki tytanu i wanadu wpływają na zwiększenie temperatury odpuszczania dzięki czemu opóźnia się proces rozkładu martenzytu [3 $\div 6]$.

Stal 4330V (CrNiMoV) jest to stal stopowa obrobiona cieplnie o wysokich własnościach wytrzymałościowych oraz plastycznych. Dzięki dodatkowi wanadu uzyskuje się w tej stali wzrost twardości oraz wytrzymałości, co jest bardzo korzystne ze względu na późniejsze zastosowanie. Stal ta wykorzystywana jest w przemyśle naftowym i gazowniczym oraz lotniczym. Wykonuje się z tej stali różnego

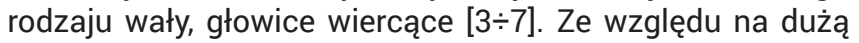
zawartość węgla (ok. 0,3\%) oraz dodatków stopowych materiał ten jest uznawany za trudno spawalny i wymagana jest obróbka cieplna złączy po spawaniu, co może wiązać się z utratą pewnych własności, dodatkowo proces spawania ze względu na ryzyko pęknięć po spawaniu, powinien być przeprowadzony z wykorzystaniem niskowodorowych procesów spawania $[1,2,6]$.

\section{Badania własne}

Celem pracy było zbadanie wpływu obróbki cieplnej po spawaniu na własności i strukturę złączy doczołowych o grubości 10 mm ze stali 4330V (skład chemiczny i własności badanej stali przedstawiono w tablicy I, II a strukturę na rysunku 1 spawanych metodą MAG drutem o średnicy 1,2 mm Böhler X 90-IG (skład masowy stopiwa oraz własności przedstawiono w tabl. III i IV) w osłonie mieszanki $\mathrm{ArCO}_{2}$ (82/18).

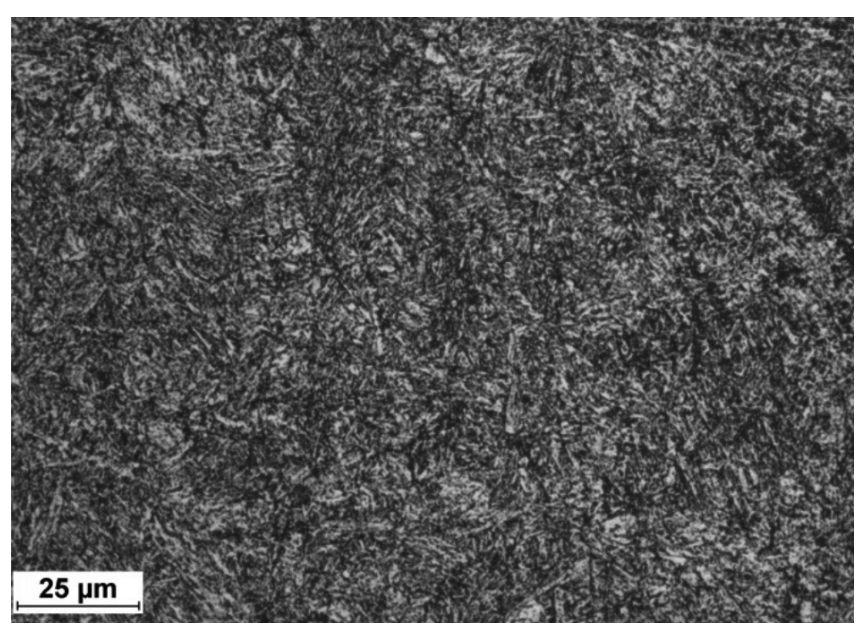

Rys. 1. Mikrostruktura stali $4330 \mathrm{~V}$

Fig. 1. Microstructure of $4330 \mathrm{~V}$ steel

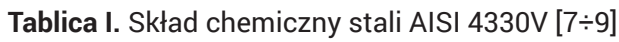

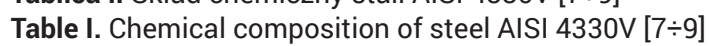

\begin{tabular}{|c|c|c|c|c|c|c|c|c|c|c|c|c|c|}
\hline \multirow{2}{*}{ Próbka } & \multicolumn{13}{|c|}{ Stężenie pierwiastków, [\%] } \\
\hline & C & $\mathrm{Cr}$ & $\mathrm{Ni}$ & Mn & Mo & Si & $\mathbf{P}$ & S & $\mathrm{Cu}$ & Al & $\mathrm{Nb}$ & $\mathrm{Ti}$ & v \\
\hline Norma & $0,3-0,34$ & $0,75-1,0$ & $1,65-2,1$ & $0,75-1,0$ & $0,4-0,5$ & $0,15-0,35$ & $\begin{array}{c}0,035 \\
\max \end{array}$ & $\begin{array}{c}0,035 \\
\max \end{array}$ & -* & $\begin{array}{r}0,015 \\
-0,035\end{array}$ & -* & -* & $0,05-0,1$ \\
\hline P1 & 0,31 & 0,99 & 1,84 & 0,9 & 0,43 & 0,26 & 0,012 & 0,00 & 0,17 & 0,03 & 0,029 & 0,008 & 0,06 \\
\hline
\end{tabular}

*- nie oznaczono

Tablica II. Własności stali AISI 4330V [8]

Table II. Properties of steel AISI 4330V [8]

\begin{tabular}{|c|c|c|c|c|}
\hline $\begin{array}{l}\text { Umowna granica } \\
\text { plastyczności } R_{0,2} \text { *, } \\
\text { [MPa] }\end{array}$ & $\begin{array}{l}\text { Wytrzymałość na } \\
\text { rozciąganie } R \mathbf{R m} \text { *, } \\
\text { [MPa] }\end{array}$ & $\begin{array}{c}\text { Wydłużenie } A^{*} \text {, } \\
{[\%]}\end{array}$ & $\begin{array}{c}\text { Praca tamania KV } \\
\left(-40^{\circ} \mathrm{C}\right) * \\
{[\mathrm{~J}]}\end{array}$ & Twardość HRC* \\
\hline 1000 & 1140 & 19 & 89 & 34,4 \\
\hline
\end{tabular}

Tablica III. Skład chemiczny stopiwa Böhler X 90-IG [10]

Table III. Chemical composition of Böhler X 90-IG [10]

\begin{tabular}{|c|c|c|c|c|c|}
\hline \multicolumn{7}{|c|}{ Stężenie pierwiastków, [\%] } \\
\hline C & Cr & Ni & Mn & Mo & Si \\
\hline 0,1 & 0,35 & 2,25 & 1,8 & 0,6 & 0,8 \\
\hline
\end{tabular}

Tablica IV. Własności drutu Böhler X 90-IG [10]

Table IV. Properties of Böhler X 90-IG wire [10]

\begin{tabular}{|c|c|c|c|}
\hline $\begin{array}{c}\text { Umowna granica } \\
\text { plastyczności } \mathbf{R}_{0,2} * \\
{[\mathrm{MPa}]}\end{array}$ & $\begin{array}{c}\text { Wytrzymałość na } \\
\text { rozciąganie } \mathbf{R m} * \\
{[\mathrm{MPa}]}\end{array}$ & $\begin{array}{c}\text { Wydłużenie } \mathrm{A}^{*}, \\
{[\%]}\end{array}$ & $\begin{array}{c}\text { Praca tamania KV } \\
\left(-60^{\circ} \mathrm{C}\right) * \\
{[\mathrm{~J}]}\end{array}$ \\
\hline 890 & 940 & 16 & 47 \\
\hline$*$ - Wartości minimalne & & \\
\hline
\end{tabular}


Tablica V. Parametry procesu spawania

Table V. Parameters of the welding process

\begin{tabular}{|c|c|c|}
\hline \multicolumn{3}{|c|}{ Parametry spawania } \\
\hline $\begin{array}{c}\text { Natężenie prądu I, } \\
\text { [A] }\end{array}$ & Napięcie łuku U, \\
{$[\mathrm{V}]$} & $\begin{array}{c}\text { Prędkość podawania drutu V, } \\
{[\mathrm{m} / \mathrm{min}]}\end{array}$ \\
\hline
\end{tabular}

\section{Wykonanie złączy próbnych}

Do procesu spawania użyto stali 4330V o grubości $10 \mathrm{~mm}$ z ukosowaniem typu V. Spawanie wykonano metodą MAG z użyciem materiału dodatkowego Böhler $X$ 90-IG o średnicy $1,2 \mathrm{~mm}$ w osłonie mieszanki gazowej $\mathrm{Ar}+\mathrm{CO}_{2}\left(18 \% \mathrm{CO}_{2}\right)$. Parametry procesu spawania przedstawia tabl. V. Ściegi wykonywano w pozycji podolnej, z wstępnym podgrzaniem materiatu do temperatury około $300{ }^{\circ} \mathrm{C}$. W celu zachowania stałych warunków spawania na całej długości spoiny wykorzystano płyty dobiegowe i wybiegowe. Podczas procesu spawania kontrolowano temperaturę, która nie przekraczała $400{ }^{\circ} \mathrm{C}$.

\section{Obróbka cieplna złączy próbnych}

Po przeprowadzonym procesie spawania złączy, przystąpiono do obróbki cieplnej polegającej na podgrzewaniu materiału z piecem do temperatury odpuszczania $(175,275$, $575^{\circ} \mathrm{C}$ ) i następnym wygrzewaniu w tej temperaturze przez 5 h (rys. 2). Po obróbce złącza były chłodzone w powietrzu.

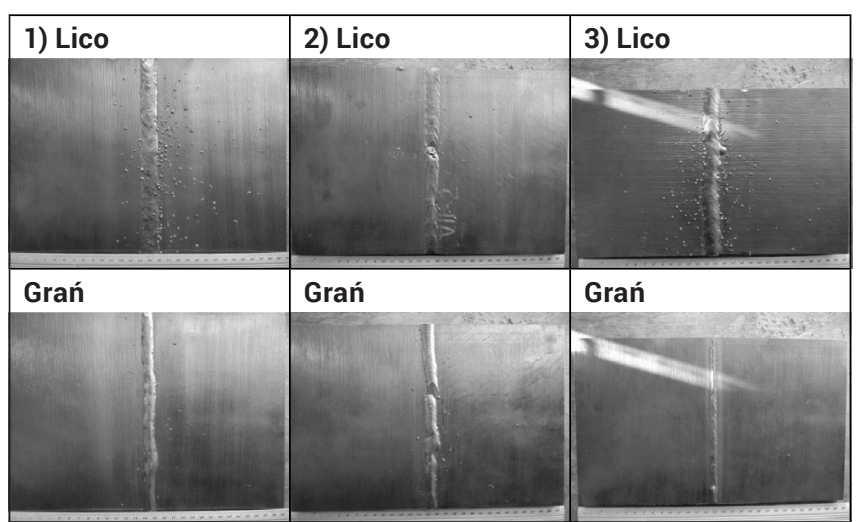

Rys. 2. Złącza po spawaniu i obróbce cieplnej w temperaturze odpuszczania: 1) $\left.\left.175^{\circ} \mathrm{C}, 2\right) 275^{\circ} \mathrm{C}, 3\right) 575^{\circ} \mathrm{C}$

Fig. 2. Joints after welding and heat threatment in temperature $175^{\circ} \mathrm{C}$, 2) $\left.275^{\circ} \mathrm{C}, 3\right) 575^{\circ} \mathrm{C}$

\section{Badania złączy}

Złącza po spawaniu i odpuszczaniu zostały poddane badaniom:

- wizualnym na podstawie wymagań PN-EN ISO 17637,

- penetracyjnym na podstawie wymagań PN-EN ISO 3452,

- metalograficznym makroskopowym na mikroskopie świetlnym Olympus SZX9; próbki trawiono w nitalu,

- metalograficznym mikroskopowym na mikroskopie świetlnym NIKON ECLIPSE MA100; próbki trawiono w nitalu,

- pomiaru twardości metodą Vickersa na urządzeniu VEP Lipsk HPO-250 na podstawie wymagań PN-EN ISO 15614-1. Badania przeprowadzono w dwóch liniach pomiarowych leżących o $2 \mathrm{~mm}$ poniżej górnej i dolnej powierzchni spawanego złącza. Schemat pomiarów twardości przedstawia rysunek 3.

- wytrzymałości na rozciąganie, przeprowadzonym na maszynie wytrzymałościowej UTS-250 na podstawie wymagań PN-EN ISO 6892-1. Badania przeprowadzono w $20^{\circ} \mathrm{C}$,

- próbie udarności metodą Charpy'ego młotem wahadłowym na podstawie wymagań PN-EN ISO 148-1. Badanie przeprowadzono $\mathrm{w}$ temperaturze $-40{ }^{\circ} \mathrm{C}$, próbka standardowa 10x10x55 mm z karbem typu V 2 mm. Próby wykonano w spoinie oraz w SWC.

- próbie zginania złączy na prasie hydraulicznej na podstawie wymagań PN-EN ISO 5173. Próba zginania poprzecznego przeprowadzona od strony grani, walec gnący o średnicy $40 \mathrm{~mm}$.

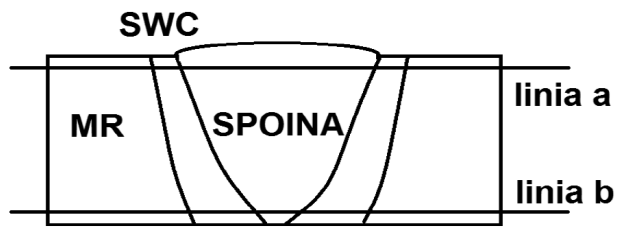

Rys. 3. Schemat linii pomiaru twardości

Fig. 3. Schematic line measuring hardness

\section{Analiza wyników badań}

Przeprowadzone badania wizualne otrzymanych złączy próbnych (rys. 2) wykazały niezgodności spawalnicze typu rozprysk. W złączu 2 stwierdzono występowanie skupiska porowatości oraz niepełne wypełnienie rowka. W złączu 3 zaś stwierdzono nieznaczne wklęśniecie lica.

Badania penetracyjne wykonano od strony lica (rys. 4). W wyniku badań nie stwierdzono wskazań w obrębie linii wtopienia, co może sugerować brak pęknięć w tych miejscach. W przypadku złącza 2 uwidoczniły się pory powstałe na licu oraz niepełne wypełnienie rowka.

Wykonane badania makrostruktury (rys. 5) nie uwidoczniły widocznych niezgodności wewnętrznych. Stwierdzono występowanie pełnego przetopu w złączach. W wyniku badań mikrostruktury (rys. 6) stwierdzono strukturę martenzytyczną SWC w wyniku odpuszczania w temperaturze $175^{\circ} \mathrm{C}$. Wyższe temperatury odpuszczania doprowadziły do ujawnienia struktury martenzytu odpuszczonego z rozrostem ziarna wraz z zwiększaniem temperatury odpuszczania. Struktura spoiny ujawniła martenzyt odpuszczony z niewielkim udziałem bainitu. Wraz z zwiększaniem temperatury odpuszczania wielkość ziarna rosła.
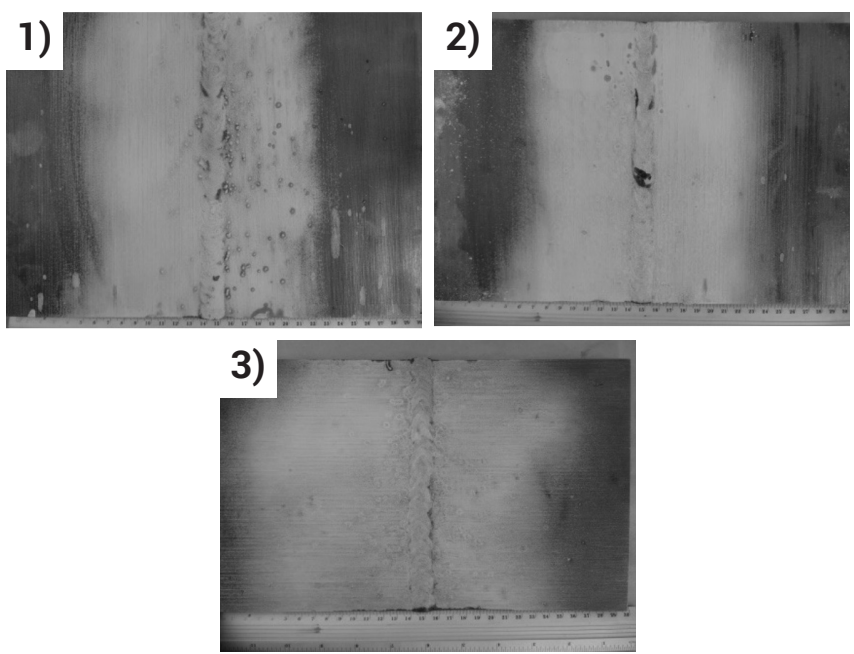

Rys. 4. Badania penetracyjne złączy

Fig. 4. Penetrant testing of joints 


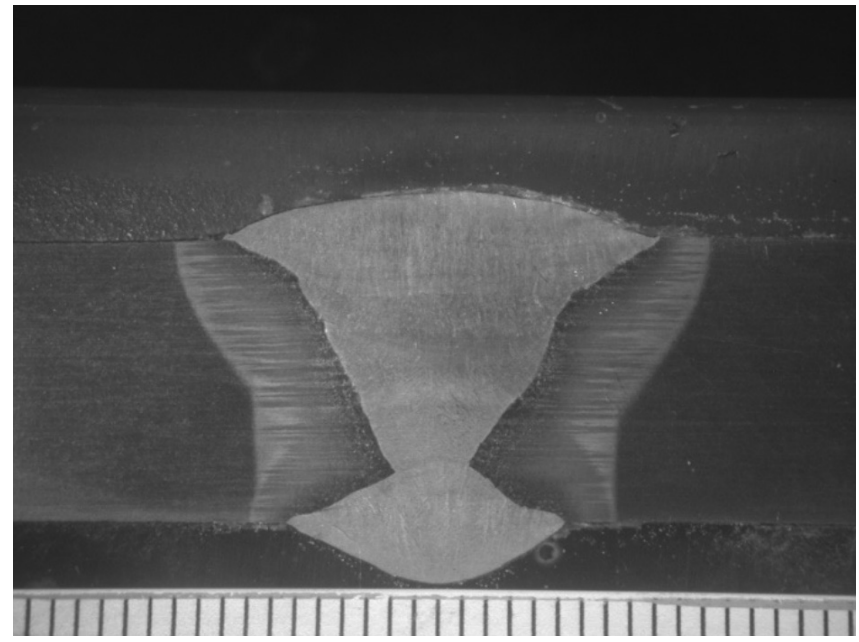

Rys. 5. Widok makrostruktury złącza 1

Fig. 5. View macrostructure joint 1
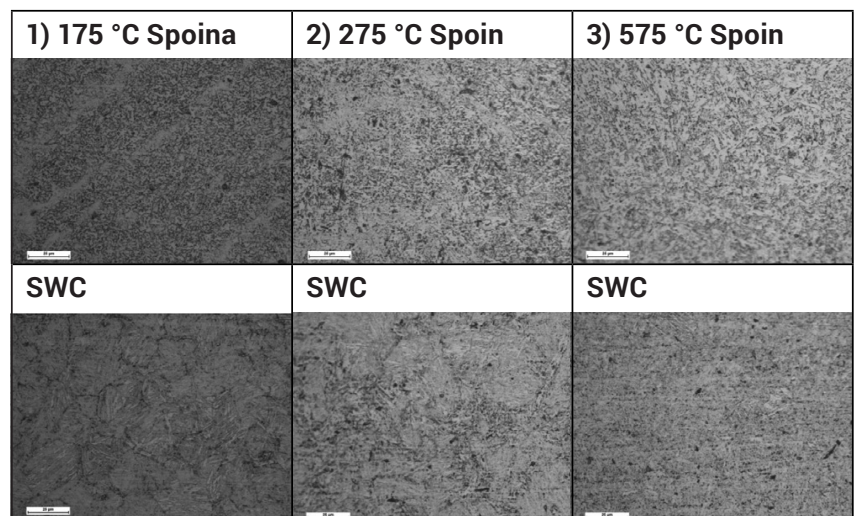

Rys. 6. Widok mikrostruktury złączy spawanych

Fig. 6. View mikrostructure weld joints

Przeprowadzone badania twardości (rys. 7) wykazały brak wzrostu twardości w materiale rodzimym po obróbce cieplnej, oscylowała ona w granicach $340 \mathrm{HV}$. W przypadku SWC wraz z wzrostem temperatury odpuszczania zmniejsza się twardość w tym obszarze z ok. $550 \mathrm{HV}$ w przypadku złącza 1 do ok. $330 \mathrm{HV}$ w przypadku złącza 3 . Wskazuje to na znaczne odpuszczenie i potwierdza zmiany struktury w SWC. Twardość w spoinie jest na stałym poziomie w wszystkich przypadkach (około $320 \mathrm{HV}$ ), nieznacznie następuje wzrost twardości w przypadku złącza 2 do około $350 \mathrm{HV}$.

Badania wytrzymałości na rozciąganie (rys. 8) wykazały wartość wytrzymałości na rozciąganie na poziomie wytrzy-

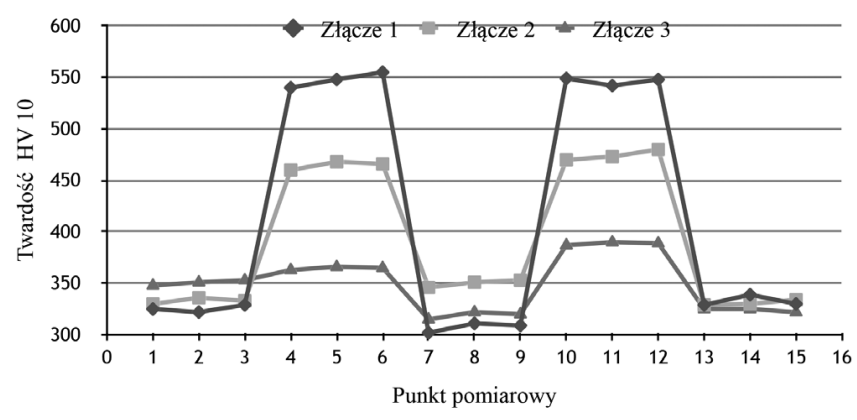

MR SWC SPOINA SWC MR

Rys. 7. Wyniki pomiarów twardości. Linia a

Fig. 7. Results of hardness measurement. Line a

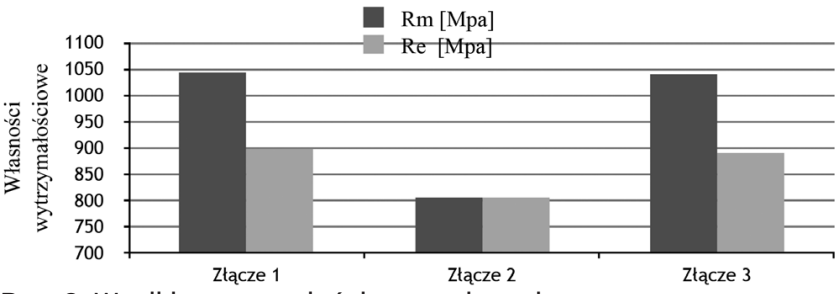

Rys. 8. Wyniki wytrzymałości na rozciąganie

Fig. 8. The results of the tensile strength

małości materiału dodatkowego. Osiągnięto wytrzymałość w granicy 1040 MPa w przypadku złączy 1 i 3, w złączu 2 ujawniono widoczny spadek wytrzymałości do poziomu $800 \mathrm{MPa}$. Wydłużenie osiągnęło wartość około $10 \%$ w przypadku złączy 1 i 3, w złączu 2 było one bliskie zeru.

Badania udarności (rys. 9) złączy próbnych wykazały wzrost wartości pracy łamania w stosunku do materiału rodzimego przed spawaniem. W przypadku złącza 2 nawet do 160 J. Praca łamanie w spoinie złącza 1, 2 była na poziomie $50 \mathrm{~J}$, w połączeniu nr 3 nastąpił widoczny spadek wartości pracy łamania do około $5 \mathrm{~J}$.

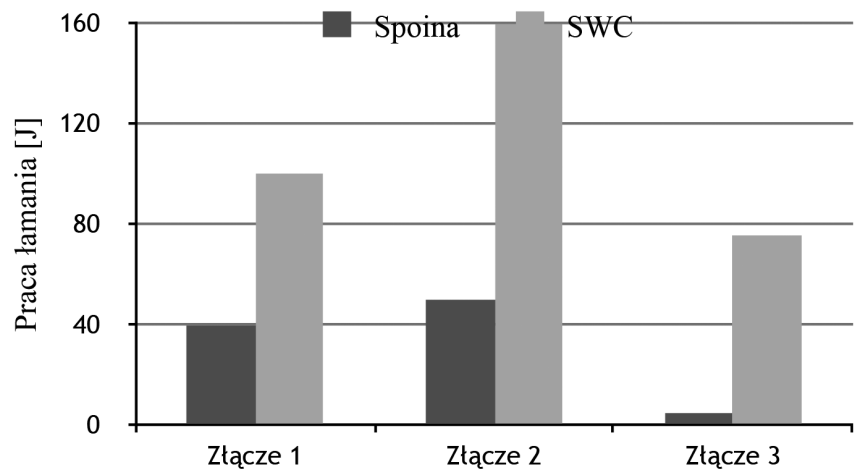

Rys. 9. Wyniki badań udarności

Fig. 9. Impact test results

Próby zginania wykonane na złączach próbnych (rys. 9) ujawniły pęknięcia w złączach 2 i 3 . Złącze 1 uzyskało kąt gięcia bliski $180^{\circ}$. Może to sugerować dobre własności takiego złącza w późniejszej eksploatacji.
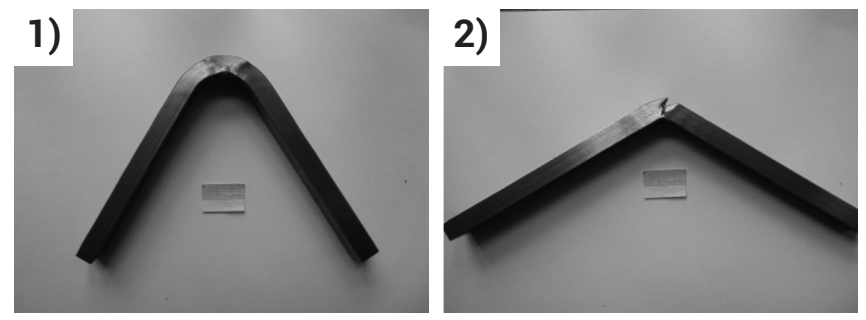

3)

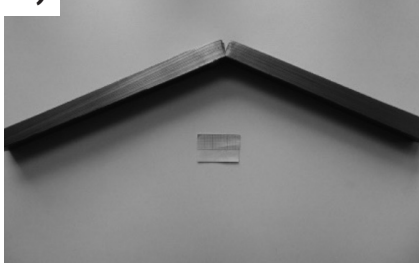

Rys. 10. Złącza po próbie zginania

Fig. 10. Joints after the bending test 


\section{Podsumowanie}

W wyniku przeprowadzonych badań złączy próbnych ze stali 4300V spawanych metodą MAG z użyciem drutu X 90-IG, poddanym procesom odpuszczania, można stwierdzić, że istnieje możliwość wykonania złączy o wysokich własnościach wytrzymałościowych. Analiza mikrostruktury ujawniła strukturę martenzytyczną po spawaniu w SWC. Wraz zwiększeniem temperatury odpuszczania zmniejszała się twardość w tym obszarze, w wyniku czego w przypadku złącza nr 3 jest ona na poziomie materiału rodzimego. Proces odpuszczania nie wpłynął na obniżenie własności wytrzymałościowych w przypadku skrajnych temperatur odpuszczania. Spoina charakteryzuje się strukturą odpuszczonego martenzytu z bainitem, jej twardość jest zbliżona do materiału rodzimego. W wyniku przeprowadzonych badań zginania uzyskano pęknięcia w dwóch złączach (2,3). Dzięki analizie wyników struktury oraz badań niszczących można stwierdzić, że najkorzystniejszą obróbką cieplną złączy stali 4330V spośród przebadanych jest odpuszczanie w temperaturze $175^{\circ} \mathrm{C}$ w czasie 5 godzin.

\section{Literatura}

[1] C. Mikia. K. Homma, T. Tominaga, High strength and high performance steels and their use in bridge structures, Journal of Constructional, Steel Research 58 (2002), s.3-20.

[2] C. Lee. H. Shin. K. Park, Evaluation of high strength TMCP steel weld for use in cold regions, Journal of Constructional Steel Research 74 (2012), s.134-139.

[3] J. Pacyna, R. Dąbrowski, Wpływ wanadu na przemiany przy odpuszczaniu stali o małej zawartości innych pierwiastków, 12 th International Scientific Conference. Achivements in mechaanical and material engenering, s. 713-718.

[4] S. Rudnik, Metaloznawstwo, Państwowe Wydawnictwo Naukowe, Warszawa 1980r.

[5] K. Przybyłowicz, Metaloznawstwo, Wyd. WNT, Warszawa 2007r.

[6] J. Górka, Własności i struktura złączy spawanych stali obrabianej termoplastycznie o wysokiej granicy plastyczności, Wyd. Pol. Śl., Gliwice 2013.

[7] AISI 4330V TATA Steel, 2015r.

[8] Certyfikat jakości stali 4330V.

[9] www.westyorkssteel.com, Karta charakterystyki stali 4330V.

[10] www.boehler-welding.com, Karta charakterystyki Böhler X 90-IG. 